\title{
The Childbirth Fear Questionnaire: A New Measure of Fear of Childbirth
}

\author{
Nichole Fairbrother ( $\nabla$ nicholef@uvic.ca ) \\ University of British Columbia \\ Fanie Collardeau \\ University of Victoria \\ Arianne Albert \\ Women's Health Research Institute \\ Dana Thordarson \\ University of British Columbia \\ Kathrin Stroll \\ University of British Columbia
}

\section{Research Article}

Keywords: childbirth, fear, assessment, birth, questionnaire development, cesarean, vaginal

Posted Date: June 14th, 2021

DOI: https://doi.org/10.21203/rs.3.rs-568026/v1

License: (c) (1) This work is licensed under a Creative Commons Attribution 4.0 International License. Read Full License 


\section{Abstract \\ Background}

Fear of childbirth affects as many as $20 \%$ of pregnant people, and has been associated with pregnancy termination, prolonged labour, increased risk of emergency and elective caesarean delivery, poor maternal mental health, and poor maternal-infant bonding. Currently available measures of fear of childbirth fail to fully capture pregnant people's childbirth-related fears. The purpose of this research was to develop a new measure of fear of childbirth (the Childbirth Fear Questionnaire; CFQ) that would address the limitations of existing measures.

\section{Methods}

The CFQ's psychometric properties were evaluated through two studies. Participants were 643 pregnant people residing in English speaking countries for study one, and 881 pregnant people residing in Canada for study two. In both studies, participants completed a set of questionnaires, including the CFQ, via an online survey.

\section{Results}

Exploratory factor analysis in study one resulted in a 40-item, 9-factor scale which was well supported in study two. Both studies provided strong evidence of high internal consistency and as well as convergent and discriminant validity. Study one also provided evidence that the CFQ detects group differences between pregnant people across mode of delivery preference, and parity. Study 2 added to findings from study 1 by providing evidence for the dimensional structure of the construct of fear of childbirth, and measurement invariance across parity groups (i.e., the measurement model of the CFQ is generalizable across parity groups).

\section{Conclusions}

The CFQ is psychometrically sound, and currently the most comprehensive measure of fear of childbirth currently available. The CFQ covers a broad range of domains of fear of childbirth, and can serve to identify specific fear domains to be targeted in treatment.

\section{Background}

Worldwide, approximately 137 million births occur each year, with over 300,000 babies born in Canada alone (1). Maternal mortality is lowest in high income countries (2). Specifically, in 2017 the maternal mortality ratio (MMR: the number of maternal deaths per 100,000 live births, and a measure of the overall quality of maternal health and reproductive care) was 11 per 100000 live births in high income countries (2). The MMR is estimated at 10 for Canada and 19 for the United States (3). In low-income countries, maternal mortality is higher, with 462 death per 100000 live births (2). Globally, from 2000 to 2017 , the MMR dropped by $38 \%$ (2). However, despite the relative safety of childbirth in developed nations, many pregnant people nevertheless experience high levels of fear of childbirth.

Pregnancy and childbirth are significant, emotionally powerful life events. For many childbearing people, pregnancy follows a complex emotional trajectory characterized by both positive and negative feelings in anticipation of their due date $(4,5)$. While positive feelings usually outweigh negative feelings, including worries about childbirth, for some, negative emotions, including fear related to giving birth, predominate (6). Despite the relative safety of childbirth in high income settings, pregnant people may experience fear about being unable to prepare for the unpredictable, the amount of pain they will experience during labour and birth, the possible medical procedures that may be required (e.g. caesarean), as well as concerns for the health and wellbeing of themselves and their newborn $(4,6)$.

Clinically significant levels of fear of childbirth have been found to affect as many as $4.5 \%$ of pregnant people $(7,8)$. With one exception $(8)$, levels of fear of childbirth have typically been found to be higher among nulliparous people $(7,9,10)$ compared with multiparous people. Fear of childbirth has also been associated with a range of negative outcomes including: avoidance of pregnancy, termination of pregnancy, higher levels of perceived pain during childbirth, increased length of labour, increased likelihood of emergency and elective caesarean birth, postnatal depression and posttraumatic stress disorder, increased parenting stress, and poor maternal-infant bonding $(9,11-15)$. There are, however, opportunities to mitigate these negative effects. Previous research has shown that psychotherapy and educational interventions, such as counselling delivered by maternity care providers or education on childbirth at the hospital, can reduce pregnant people's fears of childbirth (16). Additionally, although medical indications for caesarean birth have been wellestablished, to our knowledge, there are few established psychosocial indications. Persistent, untreated fear of childbirth which is clinically distressing or impairing may justifiably be one such indication.

\section{Measurements of Fear of Childbirth}

Although numerous measures of childbirth fear have been reported in the literature ranging in length from a single item to 53 items, each of them either: (a) assesses only a subset of the content domains relevant to fear of childbirth (4,17-27), (b) includes only one or two items for some of the domains assessed $(4,28)$, (c) includes non-fear-related items $(4,17-20,26,29)$, (d) are specific to a particular subpopulation (e.g., adolescents, those who have already given birth) $(17,26)$, or (e) are single or double item measures only (22-25). See Table 1 for details. 
In our opinion, one or two item measures are insufficient to produce a stable estimate of childbirth fear, or encompass the possible range of concerns experienced by people who are pregnant or may become pregnant (e.g., fear of harm, medical interventions, or pain). Further, evidence suggests that fear of childbirth is multidimensional $(4,6,30)$. Among the longer scales developed $(4,18,21)$ each either fails to assess key domains of childbirth fears $(e . g .$, pain, harm to self or infant), includes non-fear relevant items, or under-samples content domains (i.e., have only one or two items for a particular content domain, whereas a minimum of three is needed to produce a stable measure).

By far the most commonly used measure of fear of childbirth is the Wijma Delivery Expectancy/Experience Questionnaire Version A (W-DEQ-A) (18). The WDEQ-A has been used in several countries (12,31-39). The W-DEQ-A has been found to possess good psychometric properties (12,18,40). Although the psychometric properties of the W-DEQ-A have been well established $(12,18)$, it is not limited to an assessment of fear, but rather assesses a wide range of perceptions of labour and delivery (e.g., During labour and delivery, do you think you will feel: lonely; strong; confident; afraid; deserted; weak; safe; independent; desolate; tense; happy, etc.). In factor analytic studies of the W-DEQ-A, fear has been found to emerge as one of four or one of six factors, strongly suggesting that the W-DEQ-A is not only a measure of fear $(12,18)$. Further, many aspects of fear of childbirth are not addressed in this measure (e.g., pain; perceptions of social embarrassment; pressure to receive/avoid pain medication; mother's safety; changes to the body and sexual function; fear of medical interventions). The W-DEQ-A may limit researchers' ability to assess whether specific aspects of fear of childbirth are predicted by different life experiences and/or result in differing outcomes. At the same time, the broad nature of W-DEQ-A items may still capture participants' experience of fear of childbirth albeit in a general way (i.e., still report fear, even if the exact content of their fear of childbirth would not be known).

Accurate measurement of fear of childbirth is important in correctly identifying those experiencing high levels of fear of childbirth, as well as identifying targets for treatment. At present, currently available measures of fear of childbirth do not fully meet this standard.

\section{The Present Studies}

We sought to develop a self-report measure of fear of childbirth that recognizes the complexity of childbirth fear, and assesses fear of birth regardless of the planned or preferred mode of delivery. The purpose of this paper is to describe the psychometric development of the Childbirth Fear Questionnaire (CFQ). In study one, we conducted an exploratory factor analysis of the proposed items, and identified the items and subscales for Study 2 . We also assessed the reliability, and convergent and discriminant validity of the measure. In Study 2, we evaluated the replicability and generalizability of the factor structure of the CFQ and conducted further reliability, and convergent and discriminant validity evaluations.

\section{Study 1}

\section{Methods}

\section{Participants}

We recruited English speaking, pregnant people who were over the age of 18 and who were residing in an English language country to participate, via online forums frequented by pregnant people (e.g., pregnancy-related web sites and blogs). We planned for a sample size of approximately 500 individuals, following the recommendations of MacCallum et al. (41) for the sample size needs of an exploratory factor analysis (EFA). Our final sample consisted of 643 pregnant people.

\section{Procedures}

Prospective participants were directed to the online survey via the study advertisement. In order to proceed and complete the survey, participants were required to acknowledge that they had read the study cover sheet/consent form and agreed to participate. For each survey completed, $\$ 0.50$ was donated to the Children's Health Foundation of Vancouver Island, British Columbia. The study was approved by the Behavioural Research Ethics Board of the University of British Columbia.

\section{Measures}

Background Questions. Participants completed a set of demographic questions (e.g., age, marital status, education, income, country of residence, and race and ethnicity), questions about the current pregnancy (e.g., method of conception, and number of fetuses), and previous pregnancies (if applicable) (e.g., the number of prior pregnancies, births, miscarriages, and vaginal and cesarean deliveries).

Birth Preferences. Using a 7-point Likert-type scale (ranging from a very strong preference for a vaginal birth to a very strong preference for a cesarean birth), participants were asked about mode of delivery preference (i.e., vaginal versus cesarean).

Childbirth Fear Questionnaire (CFQ) - Initial Item Pool. The initial pool for the CFQ comprised 49 items. We initially developed 49 items covering the following domains of potential childbirth-related fear: social embarrassment (e.g., fear of losing control), pain (i.e., fear of pain), pain medication (e.g., fear of not receiving the pain medication one is hoping for), mode of delivery (e.g., fear of a cesarean delivery), baby's and mother's physical safety (e.g., fear that one's infant may be harmed or die during labour/delivery), changes to one's body (e.g., scarring), sexual functioning (e.g., enjoying sexual activity less following delivery), and medical interventions (e.g., fear of having an episiotomy). CFQ items are scored on a 0 (not at all) to 4 (extremely) point, Likert-type scale.

CFQ items and item domains were developed by a team of perinatal researchers from the fields of psychology, midwifery and nursing, and based on earlier work in this area, including our own (42) The CFQ includes dimensions of fear that are commonly reported by pregnant people, such as fear of pain and fear 
that harm might come to the baby $(30,43)$. In earlier work (42), maternal complications, feelings of embarrassment, fear of medical interventions/surgery, scarring, sexual functioning, and body damage, were also identified as areas of childbirth related fear and concern, and were considered when developing the items for the CFQ.

Our group of investigators collaborated in generating items for inclusion in the CFQ, reviewing item wording, and ensuring that all domains of fear deemed relevant to childbirth had been included in the initial pool of items. In recognition of the likelihood that the CFQ would include both a total scale score and subscale scores, we developed multiple items for each fear domain (a minimum of three items per subscale are needed to ensure a reasonable degree of internal consistency reliability). In order to be able to reduce the overall number of items, and develop subscales with high internal consistency reliability, each content domain initially included five or more items.

Wijma Delivery Expectancy Questionnaire (W-DEQ-A). The W-DEQ-A is a 33-item questionnaire, with items scored on a 0-5 Likert type scale, and a range of possible scores from 0 to 165. The psychometric properties of this assessment tool have been well established $(12,18)$. In the current sample, the internal consistency reliability for the W-DEQ-A was 0.92 . In addition to the W-DEQ-A total score, there is also data to support the use of a 6-item fear scale (44).

In this study, in error, we administered the W-DEQ-A using a 0-4 Likert type scale (rather than the usual 0-5 scale). We then prorated the W-DEQ-A scores to the more standard 0-5 point scale as follows: original W-DEQ-A score divided by four, multiplied by 5 . Our rescaled mean W-DEQ-A ( $M=55.9)$ score is consistent with those found in the literature which range from 52.9 to 68.3 (9). Our mean scores for both nulliparous (60.7) and multiparous people (50.2) were consistent with those reported in the literature (i.e., 54.1 to 68.51 and 50.3 to 60.7 , respectively), as was the percentage of participants scoring above 85 (i.e., $7.5 \%$ to $15.6 \%$ in the literature, and $9.8 \%$ in the current study) (9). We are confident that our prorated W-DEQ-A scores are a valid estimate of correctly scaled W-DEQ-A items, and are valid to use as the main measure of convergent validity.

Edinburgh Postnatal Depression Scale (EPDS). The EPDS is a 10-item self-report screening tool for pre and postnatal depression. The sensitivity and specificity of the EPDS are in acceptable ranges (65\% - 100\%, and $49 \%-100 \%$, respectively) (45). The EPDS is the most widely used screening tool for perinatal depression (46). It was included in this study as a measure of discriminant validity for the CFQ; childbirth fear should be no more than moderately correlated with depression. In the current sample, the internal consistency reliability of the EPDS was 0.88 .

Mutilation Questionnaire (MQ). The MQ is a 30-item measure of blood and injury fears. Internal consistency for the MQ ranges from 0.75 to 0.86 (47). In the current sample, the internal consistency reliability was 0.87 . High MQ scores are associated with fainting at the sight of blood and injury (47,48). The MQ was included as a second measure of discriminant validity for the CFQ; blood-injury fears should be no more than moderately correlated with fear of childbirth.

\section{Data Analysis Strategy.}

Factor analyses were performed in $R$ (v. 3.3.2) (49) using the psych() package (v. 1.6.9) (50) for fitting exploratory factor analysis models. Accompanying visualizations were created using the ggplot20 package (v. 2.2.1) (51). Differences between correlations were tested using a test provided by Lee and Preacher (52), and standardized mean-difference effect sizes for t-tests $\left(d_{s}\right)$ were estimated using the calculator provided by Lakens $(53)$. All other analyses were carried out using IBM SPSS Statistics (v23).

Exploratory Factor Analysis. We followed the recommendations of Sakaluk and Short (54) and others (e.g., (55)) for conducting exploratory factor analysis on all CFQ items. Specifically, all solutions extracted common factors via maximum likelihood estimation, in order to facilitate the calculation of model fit indices. We determined the number of factors to retain through a combination of criteria, including: (1) parallel analysis (56); (2) the minimum average partial (MAP) criterion (57); (3) interpretations of absolute and relative indexes of model fit (the root mean square error of approximation [RMSEA], and Tucker-Lewis Index [TLI], respectively) (58); (4) interpretations of the Bayesian Information Criterion (BIC); (5) nested model comparisons using likelihoodratio tests between competing models; and (6) factor solution interpretability. All solutions were rotated to achieve simple structure and estimate factor correlations, using the oblique Oblimin method.

We considered items that loaded onto a factor at $\geq .35$ to be substantive indicators of the underlying latent construct. Items that did not load onto any factor beyond this threshold were determined to be poor indicators, and would be removed from the final version of the CFQ.

Reliability and Validity Analyses. The remaining analyses involved descriptive data (means, standard deviations, and percentages), Cronbach alpha reliability coefficients, correlations, and independent-samples t-tests. Differences between correlations were tested using a test of the difference between two dependent correlations with one variable in common (52).

\section{Results}

\section{Demographics}

Participant demographic and reproductive information is presented in Table 2. Note that complications in the current pregnancy were reported by participants (22.9\%), and ranged broadly in severity (e.g., early spotting, anemia, pre-eclampsia). In this sample, $21.3 \%$ of participants scored a 12 or greater (common cut-score for depression) on the EPDS.

\section{Exploratory Factor Analysis of the CFQ}


Results of our parallel analysis (see Figure 1) suggested a maximum of 13 factors ought to be retained, whereas the MAP test suggested 9 factors was sufficient. We then proceeded to evaluate indexes of model fit, information criteria, and nested model comparisons for 1-13 factor solutions (see Table 3).

Each additionally extracted factor significantly improved the fit of our model. Adequate model fit based on the RMSEA was achieved from a 6-factor model onward, whereas adequate model fit based on the TLI was achieved near the 9- to 10-factor models. The BIC indicated that our models became unnecessarily complex after the 11-factor solution, and our 13-factor solution failed to converge. We therefore examined the pattern matrixes of loadings for the 9-, 10-, and 11-factor solutions.

The 9-factor solution was supported by the MAP test and had acceptable fit according to the RMSEA, and near-acceptable fit according to the TLI ${ }^{1}$; it was also the most conceptually interpretable of the three solutions we investigated in detail. The 10-factor solution, though acceptably fitting according to both the RMSEA and TLI, yielded a tenth factor that was not conceptually coherent. The 11-factor solution, finally, was also acceptably fitting, but the extracted eleventh factor had no substantially loading items. We therefore selected the 9 -factor solution as the best fitting and conceptually interpretable model of the CFQ items.

Factor loadings for the final nine factors are presented in Table 4, and represent: (1) Fear of loss of sexual pleasure / attractiveness (SEX), (2) Fear of pain from a vaginal birth (PAIN), (3) Fear of medical interventions (INT), (4) Fear of embarrassment (SHY), (5) Fear of harm to baby (HARM), (6) Fear of cesarean birth (CS), (7) Fear of mom or baby dying (DEATH), (8) Fear of insufficient pain medication (MEDS), and (9) Fear of body damage from a vaginal birth (DAMAGE). The nine CFQ factors were generally weakly-to-moderately correlated (see Table 4), with most correlations below $r=.60$. The exceptions were the Fear of loss of sexual pleasure / attractiveness and Fear of body damage from a vaginal birth $(r=.62)$, Fear of harm to baby and Fear of mom or baby dying $(r=.78)$, and the Fear of cesarean birth and Fear of medical interventions $(r=.60)$ factors, which were strongly associated.

\section{Descriptive, Reliability, and Validity Analyses}

Descriptive Analyses. Means and standard deviations for the 9 subscales, and the CFQ Total scale scores are presented in Table 6.

Reliability Analyses. The Cronbach alpha for the overall 40-item scale was 0.94 . Cronbach alphas for the individual subscales ranged from .76 to .94 . Specifically, Cronbach's alphas were .93 for Fear of loss of sexual pleasure/attractiveness, 94 for Fear or pain from a vaginal birth, .82 for Fear of medical interventions, .84 for Fear of embarrassment, .93 for Fear of harm to baby, .85 for CS, .86 for Fear of mom of baby dying, .76 for Fear of insufficient pain medication, and 85 for Fear of body damage from a vaginal birth.

Convergent/Discriminant Validity. The convergent/discriminant validity of the CFQ was assessed by comparing the relationship between the CFQ and the W-DEQ-A, and the relationships between the CFQ and measures of depressed mood (the EPDS) and blood and injury fears (the MQ). We predicted that the CFQ would correlate more strongly with both the W-DEQ-A (another measure of fear of childbirth) full scale and the W-DEQ-A fear scale than with either the MQ or EPDS(44). The correlations between the CFQ and the W-DEQ-A (full and fear scales) were $0.41(p<0.001)$ and $0.57(p<0.001)$ respectively. The correlation between the CFQ and the EPDS was $0.35(p<.001)$, and the correlation between the CFQ and the MQ was $0.28(p<0.001)$. The CFQ-W-DEQ-A (full scale) correlation was significantly greater than the CFQ-MQ correlation, $z=2.73, p=0.006$, but not the CFQ-EPDS correlation, $z=1.60, p=0.109$. The CFQ-W-DEQ-A (fear scale) correlation was significantly greater than both the CFQ-MQ correlation, $z=7.17, p<0.001$, and the CFQ-EPDS correlation, $z=6.61$, $p<0.001$.

Birth Preferences. A second approach to assessing the validity of the CFQ was to compare participants who reported a preference for a vaginal delivery to those who reported a preference for a cesarean delivery. We predicted that participants who reported a preference for a cesarean delivery would also report higher levels of fear of pain from a vaginal birth, fear of harm to baby, fear of mom or baby dying, fear of insufficient pain medication, and fear of damage to one's body from a vaginal birth, but lower levels of fear of cesarean delivery and fear of medical interventions, compared with those who reported a preference for a vaginal birth.

The majority of the people in our sample indicated a strong or a very strong preference for a vaginal childbirth (83.8\%, $\mathrm{n}=539)$, whereas only a small proportion indicated a strong or a very strong preference for a cesarean delivery $(5.1 \%, n=33)$. Consistent with the above hypotheses, compared with those who strongly preferred a vaginal birth, people who strongly preferred a cesarean delivery reported higher scores on the Fear of pain from a vaginal birth , $t(34.08)=-2.83, p=.008, d_{s}=0.68$, Fear of harm to baby, $t(570)=-2.84, p=.005, d_{s}=0.51$, Fear of mom or baby dying $, t(570)=-2.81, p=.005, d_{s}=0$ .50 , and Fear of insufficient pain medication , $t(33.50)=-5.54, p<.001, d_{s}=1.53$, subscales of the CFQ, but lower scores on the Fear of cesarean birth, $t$ $(37.22)=6.64, p<.001, d_{s}=-1.07$, and the Fear of medical interventions, $t(570)=2.15, p=.032, d_{s}=-0.39$, subscales of the CFQ. However, mean subscale scores did not differ significantly between participants who indicated a preference for a vaginal birth compared with those who indicated a preference for a cesarean birth for the Fear of loss of sexual pleasure/attractiveness, $d_{s}=0.23$, Fear of embarrassment, $d_{s}=0.05$, or the Fear of body damage from a vaginal birth, $d_{s}=0.04$, subscales of the CFQ. The means and standard deviations for these subscale differences are presented in Table 7 .

Parity. Nulliparous and multiparous participants differed significantly on six of the nine CFQ subscales, and the CFQ Total scales. In each case, nulliparous participants scored higher than multiparous participants. Specifically, nulliparous participants scored higher than multiparous participants on the CFQ factors: Fear of loss of sexual pleasure/attractiveness, $t(639.43)=6.34, p<.001, d_{s}=0.50$, Fear of pain from a vaginal birth, $t(641)=8.70, p<.001, d_{s}=$ 0.69 , Fear of embarrassment, $t(640.80)=6.29, p<.001, d_{s}=0.50$, Fear of harm to baby $t(641)=2.88, p=.004, d_{s}=0.23$, Fear of insufficient pain medication $t(639.22)=3.98, p<.001, d_{s}=0.31$, and Fear of body damage from a vaginal birth $t(641)=6.49, p<.001, d_{s}=0.51$, and $C F Q$ Total scores $t$ $(641)=5.83, p<.001, d_{s}=0.45$. Nulliparous and multiparous participants did not differ significantly on the Fear of medical interventions, $d_{s}=0.01$, Fear of cesarean birth, $d_{s}=0.13$, or the Fear of mom or baby dying subscales, $d_{s}=0.03$. Means and standard deviations by parity, are presented in Table 7 .

Page 5/21 
Country. Canadian and American participants differed on only two of nine CFQ subscales, Fear of medical interventions, $t(605)=-2.40, p=.017, d_{s}=0.21$, and Fear of cesarean birth, $t(605)=-3.00, p=.003, d_{s}=0.26$. In both instances, American participants reported higher levels of fear, though the magnitude of these nationality differences were generally smaller than those between birth preference and parity groups. Means and standard deviations by country for Canada and the US are presented in Table 7.

\section{Summary}

In our development/validation study of the initial 49 CFQ items, involving 643 pregnant people, exploratory factor analysis resulted in a 9-factor scale, supported by MAP test with acceptable fit based on RMSEA. The resulting 9 factors represent: (1) Fear of loss of sexual pleasure / attractiveness (SEX), (2) Fear of pain from a vaginal birth (PAIN), (3) Fear of medical interventions (INT), (4) Fear of embarrassment (SHY), (5) Fear of harm to baby (HARM), (6) Fear of cesarean birth (CS), (7) Fear of mom or baby dying (DEATH), (8) Fear of insufficient pain medication (MEDS), and (9) Fear of body damage from a vaginal birth (DAMAGE). Subscales were weakly to moderately correlated with a small number of strong correlations (Fear of loss of sexual pleasure/attractiveness with Fear of body damage from a vaginal birth, Fear of harm to baby with Fear of mom or baby dying, and Fear of cesarean birth with Fear of medical interventions). Cronbach alpha coefficients for the total scale and individual subscales were all above .76. Strong evidence of convergent/discriminant validity was found when comparing the 9-factor CFQ with another measure of fear of childbirth and measures of blood, injury injection fears and depressed mood. The CFQ subscale means were also compared across subgroups (e.g., preferred mode of delivery) with hypothesized differences supported by the data.

\section{Study 2}

\section{Methods}

\section{Participants}

Participants were also English-speaking, pregnant people living in Canada. Eight hundred and eighty-one $(\mathrm{N}=881)$ participants completed an online survey between 11- and 46-weeks' gestation with an average of 35-weeks.

\section{Procedures}

We recruited English speaking, pregnant people who were over the age of 18 and who were residing in Canada, via Facebook and online forums frequented by pregnant people (e.g., pregnancy-related web sites and blogs). Consenting participants completed an online survey. Participants were eligible to win one of seven $\$ 150$ prizes. The research was approved by the Behavioural Research Ethics Board of the University of British Columbia.

\section{Measures}

Participants completed an online survey. Similarly to Study 1, the online survey included the same background and demographics questions, the 40 CFQ items retained from Study 1, the W-DEQ-A (without the scoring error described in Study 1), and the EPDS. We also administered a measure of PTSD (see below) (59). The MQ was not administered to this sample.

Posttraumatic Diagnostic Scale for DSM-5 (PDS-5). The PDS-5 is a self-report tool used to assess post-traumatic stress disorder (PTSD) based on the DSM5 diagnostic criteria. The PDS-5, one of the most used self-report measures of PTSD, has been found to show good sensitivity and specificity, internal consistency and test-retest reliability, and convergent and discriminant validity $(59,60)$. A significantly elevated PDS-5 score (i.e. $\geq 28$ ) yields a sensitivity of $79 \%$ and specificity of $78 \%$, allowing for probable prediction of a PTSD diagnosis (59).

\section{Data Analysis Strategy}

Confirmatory Factor Analysis and Invariance Testing. We used confirmatory factor analysis (CFA) to test the replicability of our exploratory measurement model from Study 1; we also specified two additional methods factors that we anticipated shared variance on account of the repeated use of the terms "vaginal" (items 8, 19, 20, 31, 35, and 37) and "caesarian" (items 9, 21, and 34). Given the limited number of response options for the CFQ and that our indicators failed to meet assumptions of multivariate normality (Multivariate Skewness $p<.001$, Multivariate Kurtosis $p<.001$, univariate nonnormality for all indicators $p<.001$ ) for the default maximum-likelihood estimator, we opted instead to use a robust unweighted least squares estimator (ULSM). The model was identified and the scale of latent variables was set using a fixed-factor method, whereby latent variances were fixed to a value of 1 and all loadings were freely estimated. We evaluated models using conventional recommended cut offs for absolute and relative indexes of model fit (58,61), including the RMSEA and standardized root mean square residual (SRMR; both recommended to be <.08), and the TLI and Comparative Fit Index (CFl; both recommended to be $>.90$ ), being mindful of how model reliability can impact the appropriateness of these cut offs (see (62). We conducted our CFA using the lavaan() package (v. 0.5-23.1097) (63) for $R(64)$.

Multi-Group Measurement Invariance Testing. We then tested the generalizability of our CFA model by examining measurement invariance across participants based on their experience of pregnancy as primiparous $(n=208)$ or multiparous $(n=683)$ mothers. Establishing measurement invariance is a necessary precursor to group comparisons of factor correlations or means, in order to rule out the possibility that differences from such comparisons simply reflect divergences in the way groups think about the constructs under consideration $(61,65)$. Specifically, groups must demonstrate the same number of factors and general pattern of loadings (i.e., configural invariance) and factor loadings of comparable magnitude (i.e., weak invariance) in order for group 
comparisons of correlations involving the factors to be valid. Moreover, groups must demonstrate configural and weak invariance, alongside intercepts of comparable magnitude (i.e., strong invariance) in order for group comparisons of factor means to be valid.

We began the process of testing measurement invariance by fitting and evaluating a configural invariance model. We then used a combination of nested model comparisons and examining the change in model fit indexes in order to determine whether the constraints imposed by the subsequent levels of invariance (i.e., weak and strong) were supported (e.g., (66); (67). We fit and evaluated our invariance models using the semTools() package (v. 0.4-14) (68) for R (64), using the same scale-setting, and identification selections from our CFA analysis.

However, because of convergence issues with the USLM estimator for our invariance testing, we reverted to using a robust maximum-likelihood estimator for specifying invariance models. As a consequence, our invariance models appear worse fitting than they would have been under the more appropriate USLM estimator (e.g., there was nearly a .10 CFI difference between base models depending on estimator selection). We think this compromise is acceptable, given that with these invariance tests we were primarily concerned with relative changes in model fit as we imposed more stringent invariance constraints.

Taxometric Analyses. Our final analysis regarding the measurement structure of the CFQ involved examining whether-as our factor analysis models presumed-the CFQ was best understood as reflecting some continuous dimension(s) or rather, some number of discrete categories, using taxometric analyses (69) (for reviews see (70) and (71)). In essence, taxometric analyses function by calculating indexes that ostensibly evidence continuity vs. categorical-ness for a set of observed indicators (e.g., Mean Above Minus Below A Cut, MAMBAC), and then comparing the values of those indexes against those of the same indexes when coming from simulated populations in which a dimensional or categorical structure is specified. Specifically, a comparison curve fit index (CCFI) is computed as the ratio of the degree of misfit for the observed data to a dimensional population compared to a categorical population, with CCFI values less than .45 evidencing support for a dimensional model, values greater than .55 evidencing support for a categorical model, and values in between indicating an ambiguous outcome. Further, multiple taxometric indexes can be used to compute CCFls in this fashion; in fact, it is recommended to do so as a form of consistency testing, in order to ensure interpretations are robust to the idiosyncrasies of each index (70) We therefore evaluated CCFIs from three standardly reported taxometric indexes: MAMBAC, MAXEIG (maximum eigenvalue), and L-MODE (latent mode).

In order to conduct a taxometric analysis, we had to determine two additional analytic features: the indicators that we would include in the analysis, and the plausible size of a taxon (i.e., the first extracted category) underlying the CFQ, were a categorical solution to be supported (70). Unlike other forms of latent variable modeling, taxometrics works best when using an efficient (i.e., limited, non-exhaustive) non-redundant (i.e., spanning the conceptual breadth of the construct) set of indicators from a larger measure; in particular Ruscio et al. (72) recommends somewhere between 3-5 indicators (as cited in (71)). As the CFQ contains many more items, we therefore conducted our taxometric analyses three times, using a different sampling of items across the subscales of the CFQ for each instance (Analysis 1: items 2, 8, 34, 39; Analysis 2: items 13, 21, 24, 26, and 40; and Analysis 3: items 3, 7, 9, and 37), which provided us another opportunity to evaluate the consistency of our analyses across different analytic specifications.

Next, taxometric model fitting requires the specification of a plausible taxon base rate (see (70)) in order to compute the desired CCFI values. As a recently developed alternative to subjectively determining this base rate (e.g., by consulting previous literature, guestimating, etc.) Ruscio et al. (72) developed a method of creating CCFI profiles, in which taxometric analyses are performed iteratively across a range of specified base-rates. The CCFI profile method, though computationally more intensive, is advantageous in that it provides a reliable means of determining whether the underlying measurement model is dimensional or categorical, and, when in fact categorical, CCFI profiles provide the most accurate estimate of the true underlying base rate. We therefore used the CCFI profile method, evaluating of CCFI values (and their average) across the broadest range of taxon base rates (2.5\% to $97.5 \%$ ).

We conducted all taxometric analyses using the RTaxometrics package (73) in R (64).

Descriptive, Reliability, and Validity Analyses. The remaining analyses involved descriptive data (means, standard deviations, and percentages), Cronbach alpha reliability coefficients, and correlations. Differences between correlations were tested using a test of the difference between two dependent correlations with one variable in common (52).

\section{Results}

\section{Demographics}

Participant demographic and reproductive information is presented in Table 2.

\section{CFA and Invariance of the CFQ}

Our CFA of the exploratory measurement model from Study 1 suggested that our model fit the data extremely well, $(676)=4300.63, p<.001, \mathrm{CFI}=.977, \mathrm{TLI}$ $=.974, \mathrm{RMSEA}=.064(90 \% \mathrm{Cl}: .062, .066)$, SRMR $=.055$. Parameter estimates (see Table 8$)$ suggest that our proposed model fit cut-offs were reasonable for detecting model misspecification, as most standardized factor loadings were near or greater than the population values specified in Hu and Bentler's simulation study (62)

Our measurement invariance analyses, meanwhile, suggested that our measurement model was generalizable across parity status. Model fit was virtually unchanged moving from the non-grouped CFA model to the multi-group configural invariance model, and changes in model fit indexes between the configural invariance and loading invariant models (DCFI $=.000, \mathrm{DTLI}=.004$, DRMSEA $=-.001, \mathrm{DSRMR}=-.002, \mathrm{DBIC}=-204.51)$ and loading invariant and intercept invariant models $((\mathrm{DCFI}=-.002, \mathrm{DTLI}=.001, \mathrm{DRMSEA}=.000, \mathrm{DSRMR}=.001, \mathrm{DBIC}=-127.65)$ suggested that the added constraints on measurement parameters were reasonable.

Page $7 / 21$ 
Parity. Using structural equation modeling and comparing against the intercept-invariance model of the CFQ, we again found differences in CFQ scores based on parity, $c^{2}(9)=60.73, p<.001$. As in Study 1, nulliparous participants scored higher than multiparous participants on seven of the nine CFQ factors, including the Fear of loss of sexual pleasure / attractiveness, $z=4.78, p<.001, d_{s}=0.52$, Fear of pain from a vaginal birth, $z=2.47, p=.01, d_{s}=$ 0.19 , Fear of medical intervention, $z=2.68, p=.007, d_{s}=0.26$, Fear of embarrassment, $z=3.77, p<.001, d_{s}=0.41$, Fear of harm to baby $z=3.67, d_{s}=0.32$, Fear of mom or baby dying, $z=2.27, p=.02, d_{s}=0.20$, and Fear of body damage, $z=4.50, p<.011, d_{s}=0.37$. Nulliparous and multiparous participants did not differ significantly on the Fear of caesarian birth, $d_{s}=0.09$, Fear of insufficient pain medication, $d=0.05$.

In sum, our CFA-related analyses suggest that the measurement model of the CFQ is both replicable, and generalizable across parity groups, indicating that it is appropriate for use within (and comparisons between) samples of participants who are expecting with different levels of pregnancy experience.

\section{Taxometric structure of the CFQ}

Our three selected samplings of CFQ items generally exhibited excellent properties for candidate indicators in taxometrics analyses, in terms of distributional characteristics, validity coefficients, and within-taxon and within-compliment correlations (see $(70,71)$ All three CCFI profiles (see Figure 2) strongly supported a dimensional structure for the CFQ and its subscales, as all individual CCFIs (with the exception of one CCFI from in one CCFI profile, MAXEIG in CCFI Profile 2) and their averages, across all three analyses, unambiguously supported dimensional structure (CCFIs < .45). We take the consistency of these effects as compelling evidence that the fear of childbirth is best understood as interrelated factors on which individuals differ in degree, not kind (69).

\section{Descriptive, Reliability, and Validity Analyses}

Descriptive Analyses. Means and standard deviations for each of the 9 subscales, and the CFQ Total scale scores are presented in Table 6.

Reliability Analyses. The Cronbach alpha for the overall 40 -item scale was 0.94 , and the Cronbach alphas for the individual subscales ranged from 0.71 to 0.94 (i.e., Fear of loss of sexual pleasure/attractiveness $=.90$; Fear of pain from a vaginal birth $=.94$; Fear of medical interventions $=.78$; Fear of embarrassment $=.79 ;$ Fear of harm to baby $=.84 ;$ Fear of cesarean birth $=.87$; Fear of mom or baby dying $=.88 ;$ Fear or insufficient pain medication $=.71$; Fear of body damage from a vaginal birth $=.85)$.

Convergent/Discriminant Validity. The convergent/discriminant validity of the CFQ in Study 2 was assessed by comparing the relationship between the CFQ and the W-DEQ-A with the relationships between the CFQ and measures of depressed mood (the EPDS) and symptoms of posttraumatic stress disorder (the PDS-5). We predicted that the CFQ would correlate more strongly with both the W-DEQ-A (another measure of fear of childbirth) full scale and the W-DEQ-A fear scale (44) than with either the EPDS or the PDS-5. The correlations between the CFQ and the W-DEQ-A (full and fear scales) were 0.58 ( $p<0.001$ ) and $0.62(p<0.001)$ respectively. The correlation between the CFQ and the EPDS was $0.34(p<.001)$, and the correlation between the CFQ and the PDS-5 was $0.24(p=0.001)$. The CFQ-W-DEQ-A (full scale) correlation was significantly greater than the CFQ-EPDS correlation, $z=7.59, p<0.001$, and the CFQ-PDS-5 correlation, $z=6.97, p<0.001$. The CFQ-W-DEQ-A (fear scale) correlation was significantly greater than both the CFQ-EPDS ( $z=9.00, p<0.001$ ), and the CFQ-PDS-5 $(z=7.97, p<0.001)$ correlations. See Table 5 for a full list of correlations.

\section{Summary}

Study two supported the 9-factor structure of the CFQ, and provided evidence of measurement invariance across parity groups. Specifically, those who had previously given birth understood and responded to CFQ items in the same way as participants who had not previously given birth. Additionally, further tests of the CFQ's latent structure strongly supported a dimensional structure. Thus, fear of childbirth is a construct on which individuals differ in degree rather than in kind (i.e., higher fear of childbirth is not qualitatively different from a lower fear of childbirth). As in study one, the CFQ demonstrated good reliability, and convergent and discriminant validity. As was true in study one also, overall, nulliparous participants scored higher on CFQ subscales compared to multiparous participants.

\section{Discussion}

The purpose of this research was to develop a new measure of fear of childbirth that would encompass the breadth of pregnant people's childbirth fears and overcome some of the limitations of commonly used measures of fear of childbirth. Exploratory factor analysis of the CFQ resulted in a 40 -item, nine-f actor questionnaire. Our nine-factor model was supported by a MAP test, exhibited reasonable model fit and good simple structure, and our factors were readily conceptually interpretable. The 9-factor structure of the CFQ was further supported in Study 2, in a larger sample of pregnant participants. The CFQ total scale and the nine subscales demonstrated good internal consistency, and convergent and discriminant validity across both studies.

The taxometric analyses strongly supported a dimensional structure. Thus, fear of childbirth is a construct on which individuals differ in degree rather than in kind (i.e., higher fear of childbirth is not qualitatively different from a lower fear of childbirth). It also suggests that multiple causal influences with small additive effects may best explain more intense fear of childbirth (i.e., rather than a larger single causal factor). While diagnostic categories are frequently used in psychology and might be helpful for clinicians and health authorities to prioritize individuals' access to treatment, diagnostic categories hypothesize a categorical latent structure. Given the dimensional latent structure of fear of childbirth, it will be important to bear in mind that any cut-off score will be arbitrary and result in a loss of information. It is thus better for future studies to keep the full continuum of scores and respect the dimensional latent structure of the data (74). 
Second, our nine-factor model showed initial evidence of measurement invariance between parity groups. Thus, those who had previously given birth understood and responded to CFQ items in the same way as participants who had not previously given birth. Any variations in responses between those two groups will be due to real world differences, rather than to a misspecification of the measurement model for one or the other group. This is especially important, provided our finding that nulliparous participants scored higher than multiparous participants on several of the nine CFQ factors.

Data from both studies provide excellent support for the convergent and discriminant validity of the CFQ. As predicted, the CFQ correlated most strongly with another measure of fear of childbirth (W-DEQ-A), and less so with measures of depressed mood (EPDS), trauma symptoms (PDS-5) and blood, injury, injection fears (MQ). In addition, correlations with the CFQ were stronger for the W-DEQ-A (fear subscale) compared with the W-DEQ-A (full scale). This was expected and supports our contention that the W-DEQ-A is not strictly a measure of fear (i.e., includes multiple items more relevant to feelings of depressed mood and other positive and negative emotions). Although the W-DEQ-A fear subscale contains 6 items, only three truly reflect fear (i.e., afraid, tense and panic). The other three (hopelessness, pain and lose control of myself) are not specifically fear items. The weaker correlation between the CFQ and the WDEQ-A (full scale) provides support for the CFQ as a novel measure of fear of childbirth, with an emphasis on fear, and distinct from the W-DEQ-A.

Furthermore, the nine factors of the CFQ have the potential to significantly add to our knowledge about fear of childbirth. For example, the nine subscales of the CFQ, identified through factor analysis, make it evident that pregnant people's concerns about childbirth encompass a broad range of potential fears, and that pregnant people who prefer a cesarean birth have different concerns than those who prefer a vaginal birth. Findings regarding the association of CFQ domains and mode of delivery preferences are consistent with our prediction that those who strongly prefer a cesarean birth are especially fearful of

(a) the pain from a vaginal birth, and the possibility that they may not receive sufficient pain medication during labour/delivery, and (b) the possibility that something may go terribly wrong during labour/birth, and they or their infant may be harmed or die. Conversely, pregnant people who strongly prefer a vaginal birth are, as expected, more fearful of cesarean delivery and labour/birth related medical interventions in general. The same pattern of results can also be observed in the intercorrelations among the CFQ subscales.

In both studies, the lowest CFQ-W-DEQ-A subscale correlation was for the Fear of cesarean birth subscale. The Fear of medical interventions subscale also correlated weakly with the W-DEQ-A in both studies, although less so in study two (i.e., $r=.33$ and .38 in study two, and $r=.10$ and .03 in study one). This weak relationship between the W-DEQ-A and these two CFQ subscales is likely a function of the fact that the CFQ is unique among measures of fear of childbirth in its assessment of fears related to operational (i.e., cesarean) delivery.

These finding highlight an interesting phenomenon, not easily assessed by previously available measures of fear of childbirth: that some pregnant people strongly prefer a cesarean birth and are predominantly fearful of the perceived pain and/or danger associated with vaginal delivery, whereas others strongly prefer a vaginal birth and are predominantly fearful of medical interventions in general, and cesarean birth in particular. The link between fear of labour pain and a preference for cesarean delivery is well-documented $(42,75)$. Very little is known about fears specific to those who prefer vaginal birth. In this regard, the CFQ fills an important gap in our knowledge of the childbirth fears most relevant to pregnant people who prefer a vaginal birth.

The only between country (Canada and the United States) differences were for the Fear of medical interventions and the Fear of cesarean birth subscales. This is an expected finding as childbirth is a more medicalized experience in the United States in comparison with Canada (Shaw et al., 2016; Stoll et al., 2020). Previous research has shown that those who experience pregnancy in a more medicalized birth culture report heightened fear of interventions and other fears that are specific to hospital settings (76). Consequently, one would expect pregnant people's fears of medical experiences in childbirth to be heightened.

Another example, and a novel and important aspect of the CFQ, is the inclusion of subscales measuring (a) pregnant people's fears about negative, childbirth-related changes to their appearance and sexual functioning, including Fear of loss of sexual pleasure/attractiveness, and (b) Fear of embarrassment as a result of events occurring during labour/delivery (e.g., fear of urinating in front of others). It is well known that becoming a parent has a significant, and oftentimes negative, impact on one's romantic relationship, including one's sexual relationship $(77,78)$. That this is a concern for pregnant people appears well captured by the CFQ. That fears about a loss of sexual pleasure and attractiveness are associated with a fear of embarrassment during labour/delivery is not surprising in that both involve potential negative judgments by others, and potentially being seen in ways that are perceived as unattractive by typical standards. Our findings demonstrate that fears regarding embarrassment and sexual functioning/appearance are closely related to fears about childbirth pain and bodily damage in the context of a vaginal delivery, as well as harm or death to mom and baby during childbirth. It appears that pregnant people associate pain from a vaginal birth with vaginal damage, and correspondingly with negative changes to their sexual functioning and appearance, and embarrassing aspects of labour/delivery.

\section{Clinical Implications}

Current measures of fear of childbirth fail to assess the full spectrum of perinatal people's childbirth related fears. Given that fear of childbirth has been associated with a number of negative medical and social outcomes, an accurate assessment of these fears is important and has implications for pregnant individual's reproductive and mental health. The development of an effective self-report measure of fear of childbirth will facilitate: (a) the provision of appropriate treatment for those with these fears, (b) assessment of specific aspects of perinatal people's childbirth related fears, and (c) identification of fear of childbirth as a potential psychosocial indication for a cesarean delivery. The new CFQ will help to identify pregnant people's specific childbirth concerns, which may be amenable to education or a psychosocial intervention if more extreme.

\section{Limitations}

This study is limited by the fact that we collected data from two convenience samples of pregnant people. We did not collect prospective data, nor did we collect data from reproductive-aged people who are not pregnant. A further limitation is the fact that our sample was English-speaking only and

Page 9/21 
predominantly Caucasian. Generalizability of the measure is, until further validation in other cultural contexts, limited to Caucasian pregnant people living in predominantly English-speaking countries. Finally, online survey administration prevents the calculation of response rates.

\section{Future Directions}

Future research would benefit from an evaluation of the CFQ among reproductive aged people who are not pregnant but may one day become pregnant or give birth, those who are gender diverse, as well as reproductive-aged people who are biologically male. The attitudes of biologically male people towards birth and fears concerning childbirth have been shown to influence decision-making around mode of delivery (79). Further, the validity of the measure should be assessed in other cultural contexts beyond predominantly Caucasian, English-speaking countries.

In our opinion, the most important next steps in the development of the CFQ are to: (a) evaluate the test-retest reliability and sensitivity to change of the CFQ, and (b) assess the CFQ as a screening tool for specific phobia of fear of childbirth (specific phobia is the diagnostic category which has been put forth as the most appropriate classification of fear of childbirth).

\section{Conclusion}

The Childbirth Fear Questionnaire (CFQ) is a promising new instrument for the multi-factorial assessment of fear of childbirth. Evidence of its reliability and validity has been presented. We hope this new measure proves useful to identify pregnant people with elevated fear of childbirth, and for future research into the fear of childbirth.

\section{Endnote}

${ }^{1}$ We were not deeply concerned that the TLI for our 9-factor EFA model fell below the recommended value of .90. The computation of the TLI penalizes models for lack of parsimony more severely than other relative indexes of model fit (e.g., the comparative fit index, $\mathrm{CFI}$ ). As exploratory factor models are, by design, unparsimonious (i.e., every loading of every item onto every factor is estimated), the recommended cutoff-normalized in the more parsimonious CFA context (58) -is therefore very conservative in the EFA context.

\section{Abbreviations}

BIC; Bayesian Information Criterion

CCFl; Comparison Curve Fit Index

CFA; Confirmatory Factor Analysis

CFl; Comparative Fit Index

CFQ; Childbirth Fear Questionnaire

EFA; Exploratory Factor Analysis

EPDS; Edinburgh Postnatal Depression Scale

L-MODE; Latent Mode

MAMBAC; Mean Above Minus Below A Cut

MAP; Minimum Average Partial

MAXEIG; Maximum Eigenvalue

MMR; Maternal Mortality Ratio

MQ; Mutilation Questionnaire

PDS-5; Posttraumatic Diagnostic Scale for DSM-5

PDS-5; Posttraumatic Diagnostic Scale for DSM-5

PTSD; Post-Traumatic Stress Disorder

TLI; Tucker-Lewis Index

ULSM; Unweighted Least Squares Estimator

W-DEQ-A; Wijma Delivery Expectancy/Experience Questionnaire Version A 


\section{Declarations}

\section{Ethics approval and consent to participate}

Ethical approval for this study was obtained from the Behavioural Ethics Board of the University of British Columbia, and written informed consent was obtained from all participants. The University of British Columbia's Behavioural Research Ethics Board follows the Canadian Tri-Counsel Policy Statement (TCPS): Ethical Conduct for Research Involving Humans. The TCPS is in compliance with the Declaration of Helsinki.

\section{Consent for publication}

Not applicable

\section{Availability of data and materials}

The datasets used and/or analysed during the current study are available from the corresponding author on reasonable request.

\section{Competing interests}

The authors report no competing interests.

\section{Funding}

This research was funded from the primary author's start-up funds via the Island Medical Program of the University of British Columbia

\section{Authors' contributions}

NF developed the manuscript concept and was responsible for the study design. NF and FC were responsible for study design, supervision of data collection, and interpretation of the data. AA, in collaboration with NF and FC, was responsible for data analyses. All authors were involved in manuscript drafting. All authors provided scientific input and edited and reviewed the manuscript content. All authors provided their final approval ad agree to be accountable for all aspects of the work, ensuring integrity and accuracy.

\section{Acknowledgements}

The authors would like to thank the study participants for their time and thoughtful engagement. We would especially like to thank John Sakaluk for his assistance with data analyses, and Jessica Gaiptman and Stephanie Poje for their invaluable contribution to participant recruitment and data management.

\section{References}

1. Duffin E. Number of births in Canada 2000-2019. https://www.statista.com/statistics/443051/number-of-births-in-canada/. Accessed 20 February 2021.

2. World Health Organization. Maternal mortality. https://www.who.int/news-room/fact-sheets/detail/maternal-mortality. Accessed 20 February 2021.

3. The World Bank. Maternal mortality ratio (modeled estimate, per 100,000 live births). https://data.worldbank.org/indicator/SH.STA.MMRT. Accessed 20 February 2021.

4. Melender HL. Experiences of fears associated with pregnancy and childbirth: a study of 329 pregnant women. Birth. 2002;29:101-111.

5. Larkin P, Begley CM, Devane D. Women's experiences of labour and birth: an evolutionary concept analysis. Midwifery. 2009;25:e49-e59.

6. Slade P, Balling K, Sheen K, Houghton G. Establishing a valid construct of fear of childbirth: findings from in-depth interviews with women and midwives. BMC Pregnancy Childbirth 2019;19:96.

7. Zar M, Wijma K, Wijma B. Relations between anxiety disorders and fear of childbirth during late pregnancy. Clin Psychol Psychother. 2002; 9:122-130.

8. Räisänen S, Lehto S, Nielsen H, Gissler M, Kramer M, Heinonen S. Fear of childbirth in nulliparous and multiparous women: a population-based analysis of all singleton births in Finland in 1997-2010. BJOG. 2014;121:965-970.

9. Toohill J, Fenwick J, Gamble J, Creedy DK. Prevalence of childbirth fear in an Australian sample of pregnant women. BMC Pregnancy Childbirth. 2014;14:275.

10. O'Connell MA, Leahy-Warren P, Khashan AS, Kenny LC, O'Neill SM. Worldwide prevalence of tocophobia in pregnant women: systematic review and meta-analysis. Acta Obstet Gynecol Scand. 2017;96:907-920.

11. Fisher C, Hauck Y, Fenwick J. How social context impacts on women's fears of childbirth: a Western Australian example. Soc Sci Med 2006;63:64-75.

12. Johnson R, Slade P. Does fear of childbirth during pregnancy predict emergency caesarean section? BJOG. 2002;109:1213-1221.

13. Johnson R, Slade P. Obstetric complications and anxiety during pregnancy: is there a relationship? J Psychosom Obstet Gynaecol. 2003;24:1-14.

14. Klusman LE. Reduction of pain in childbirth by the alleviation of anxiety during pregnancy. J Consult Clin Psychol. 1975;43:162-165.

15. Ryding EL, Lukasse M, Parys AV, Wangel A, Karro H, Kristjansdottir H, et al. Fear of childbirth and risk of cesarean delivery: a cohort study in six European countries. Birth. 2015;42:48-55. 
16. Stoll K, Swift E, Fairbrother N, Nethery E, Janssen P. A systematic review of non-pharmacological prenatal interventions for pregnancy-specific anxiety and fear of childbirth. Birth. 2017;45:7-18.

17. Areskog B, Kjessler B, Uddenberg N. Identification of women with significant fear of childbirth during late pregnancy. Gynecol Obstet Invest. 1982;13:98.

18. Wijma K, Wijma B, Zar M. Psychometric aspects of the W-DEQ; a new questionnaire for the measurement of fear of childbirth. J Psychosom Obstet Gynecol. 1998;19:84-97.

19. Eriksson C, Westman G, Hamberg K, Medicinska fakulteten, Umeå universitet, Allmänmedicin, et al. Experiential factors associated with childbirthrelated fear in Swedish women and men: A population based study. Journal of Psychosomatic Obstetrics \& Gynecology 2005;26(1):63-72.

20. Wootton BM, Davis E, Moses K, Moody A, Maguire P. The development and initial validation of the Tokophobia Severity Scale. Clin Psychol. 2020;24:267-275.

21. Elvander C, Cnattingius S, Kjerulff KH. Birth Experience in Women with Low, Intermediate or High Levels of Fear: findings from the First Baby Study. Birth. 2013;40:289-296.

22. Haines H, Pallant JF, Karlström A, Hildingsson I, et al. Cross-cultural comparison of levels of childbirth-related fear in an Australian and Swedish sample. Midwifery. 2011;27:560-567.

23. Hildingsson I, Nilsson C, Karlström A, Lundgren I, et al. A longitudinal survey of childbirth-related fear and associated factors. J Obstet Gynecol Neonatal Nurs. 2011;40:532.

24. Laursen, Hedegaard, Johansen, Danish National Birth Cohort. Fear of childbirth: predictors and temporal changes among nulliparous women in the Danish National Birth Cohort. BJOG. 2008;115:354-360.

25. Rouhe H, Salmela-Aro K, Halmesmäki E, Saisto T. Fear of childbirth according to parity, gestational age and obstetric history. BJOG. $2009 ; 116: 1005$.

26. Saxbe D, Horton KT, Tsai AB. The Birth Experiences Questionnaire: A Brief Measure Assessing Psychosocial Dimensions of Childbirth. J Fam Psychol. 2018;32:262-268.

27. Prelog PR, Makovec MR, Šimic MV, Sršen TP, Perat M. Individual and contextual factors of nulliparas' levels of depression, anxiety and fear of childbirth in the last trimester of pregnancy: intimate partner attachment a key factor?. Zdravstveno varstvo. 2019;58:112-119.

28. Redshaw M, Martin C, Rowe R, Hockley C. The Oxford Worries about Labour Scale: women's experience and measurement characteristics of a measure of maternal concern about labour and birth. Psychol Health Med. 2009;14:354-366.

29. Slade P, Pais T, Fairlie F, Simpson A, Sheen K. The development of the Slade-Pais Expectations of Childbirth Scale (SPECS). J Reprod Infant Psychol. 2016;34:495-510.

30. Geissbuehler V, Eberhard J. Fear of childbirth during pregnancy: a study of more than 8000 pregnant women. J Psychosom Obstet Gynecol. 2002;23:229-235.

31. Bergström M, Rudman A, Waldenström U, Kieler H. Fear of childbirth in expectant fathers, subsequent childbirth experience and impact of antenatal education: subanalysis of results from a randomized controlled trial. Acta Obstet Gynecol Scand. 2013;92:967.

32. Fairbrother N, Woody SR. Fear of childbirth and obstetrical events as predictors of postnatal symptoms of depression and post-traumatic stress disorder. J Psychosom Obstet Gynaecol. 2007;28:239-242.

33. Fenwick J, Gamble J, Creedy DK, Buist A, Turkstra E, Sneddon A, et al. Study protocol for reducing childbirth fear: a midwife-led psycho-education intervention. BMC Pregnancy Childbirth. 2013;13:190-190.

34. Hall WA, Stoll K, Hutton EK, Brown H. A prospective study of effects of psychological factors and sleep on obstetric interventions, mode of birth, and neonatal outcomes among low-risk British Columbian women. BMC Pregnancy Childbirth. 2012;12:78-78.

35. Jespersen C, Hegaard HK, Schroll A, Rosthøj S, Kjærgaard H. Fear of childbirth and emergency caesarean section in low-risk nulliparous women: a prospective cohort study. J Psychosom Obstet Gynecol. 2014;35:109-115.

36. Ryding E, Wijma B, Rydhstrom H. Fear of childbirth during pregnancy may increase the risk of emergency cesarean section. Acta Obstet Gynecol Scand. 1998;77:542-547.

37. Salomonsson B, Berterö C, Alehagen S, et al. Self-efficacy in pregnant women with severe fear of childbirth. J Obstet Gynecol Neonatal Nurs. 2013;42:191-202.

38. Storksen HT, Eberhard-Gran M, Garthus-Niegel S, Eskild A. Fear of childbirth; the relation to anxiety and depression. Acta Obstet Gynecol Scand. 2012;91:237.

39. Wiklund, Edman, Ryding, Andolf. Expectation and experiences of childbirth in primiparae with caesarean section. BJOG. 2008;115:324-331.

40. Speilberger CD, Gorsuch RL, Lushene RE, Vagg PR, Jacobs GA. Manual for the State-Trait Anxiety Inventory. Palo Alto, California: Consulting Psychologists Press; 1983.

41. MacCallum RC, Widaman KF, Zhang S, Hong S. Sample size in factor analysis. Psychol Methods. 1999;4:84-99.

42. Stoll K, Fairbrother N, Carty E, Jordan N, Miceli C, Vostrcil Y, et al. It's all the rage these days: university students' attitudes toward vaginal and cesarean birth. Birth. 2009;36:133-140.

43. Maier B. Women's worries about childbirth: making safe choices. Br J Midwifery. 2010;18:293-299.

44. Garthus-Niegel S, Størksen HT, Torgersen L, Von Soest T, Eberhard-Gran M. The Wijma Delivery Expectancy/Experience Questionnaire - a factor analytic study. J Psychosoma Obstet Gynecol. 2011;32:160-163. 
45. Eberhard-Gran M, Eskild A, Tambs K, Opjordsmoen S, Samuelsen So. Review of validation studies of the Edinburgh Postnatal Depression Scale. Acta Psychiatr Scand. 2001 10;104:243-249.

46. Jomeen J, Martin CR. Confirmation of an occluded anxiety component within the Edinburgh Postnatal Depression Scale (EPDS) during early pregnancy. J Reprod Infant Psychol. 2005 05;23:143-154.

47. Kleinknecht RA, Thorndike RM. The Mutilation Questionnaire as a predictor of blood/injury fear and fainting. Behav Res Ther. 1990;28:429-437.

48. Kleinknecht RA, Morgan MP. Treatment of posttraumatic stress disorder with eye movement desensitization. J Behav Ther Exp Psychiatry. 1992;23:4349.

49. R Core Team. R: A language and environment for statistical computing. 2017.

50. Revelle W. psych: Procedures for Personality and Psychological Research. Frontiers in psychology. 2016.

51. Wickham H. ggplot2: Elegant graphics for data analysis. New York, NY: Springer; 2009.

52. Lee IA, Preacher KJ. Calculation for the test of the difference between two dependent correlations with one variable in common. 2013.

53. Lakens D. Calculating and reporting effect sizes to facilitate cumulative science: a practical primer for $t$-tests and ANOVAs. Front Psychol. $2013 ; 4: 863$.

54. Sakaluk JK, Short SD. A methodological review of exploratory factor analysis in sexuality research: used practices, best practices, and data analysis resources. J Sex Res. 2017;54:1-9.

55. Fabrigar LR, Wegener DT. Exploratory factor analysis. New York, NY: Oxford University Press; 2011.

56. Horn JL. A rationale and test for the number of factors in factor analysis. Psychometrika. 1965;32:179-185.

57. Velicer WF. Determining the number of components from the matrix of partial correlations. Psychometrika. 1976;41:321-327.

58. Hu L, Bentler PM. Cutoff criteria for fit indexes in covariance structure analysis: conventional criteria versus new alternatives. Struct Equ Modeling. 1999;6:1-55.

59. Foa EB, McLean CP, Zang Y, Zhong J, Powers MB, Kauffman BY, et al. Psychometric properties of the Posttraumatic Diagnostic Scale for DSM-5 (PDS-5). Psychol Assess. 2016;28:1166-1171.

60. Mughal AY, Devadas J, Ardman E, Levis B, Go VF, Gaynes BN. A systematic review of validated screening tools for anxiety disorders and PTSD in low to middle income countries. BMC Psychiatry. 2020;20:338.

61. Little TD. Longitudinal structural equation modeling. New York, NY: Guilford Press; 2013.

62. McNeish D, An J, Hancock GR. The thorny relation between measurement quality and fit index cutoffs in latent variable models. J Pers Assess. 2018;100:52.

63. Rosseel Y. lavaan: An R package for structural equation modeling. J Stat Softw. 2012;48:1-36.

64. R Core Team. R: A language and environment for statistical computing. 2019.

65. Vandenberg RJ, Lance CE. A review and synthesis of the measurement invariance literature: suggestions, practices, and recommendations for organizational research. Organ Res Methods. 2000;3:4-70.

66. Chen F. Sensitivity of goodness of fit indexes to lack of measurement invariance. Struct Equ Modeling. 2007;14:464-504.

67. Cheung GW, Rensvold RB. Evaluating goodness-of-fit indexes for testing measurement invariance. Struct Equ Modeling. 2002;9:233-255.

68. semTools Contributors. semTools: Useful tools for structural equation modeling. 2016; Available at: https://CRAN.R-project.org/package=semTools.

69. Meehl PE. Factors and taxa, traits and types, differences of degree and differences in kind. J Pers. 1992;60:117-174.

70. Ruscio J, Haslam N, Ruscio AM. Introduction to the taxometric method: a practical guide. Mahwah, NJ: Erlbaum: Lawrence Erlbaum Associates Publishers; 2006.

71. Sakaluk JK. Expanding statistical frontiers in sexual science: taxometric, invariance, and equivalence testing. J Sex Res. 2019;56:475-510.

72. Ruscio J, Carney LM, Dever L, Pliskin M, Wang SB. Using the Comparison Curve Fix Index (CCFI) in taxometric analyses: averaging curves, standard errors, and CCFI profiles. Psych Assess. 2018;30(6):744.

73. Ruscio J, Wang S. RTaxometrics: Taxometric analysis. 2017.

74. Ruscio J, Ruscio AM. A structure-based approach to psychological assessment: matching measurement models to latent structure. Assessment. 2002;9:4-16.

75. Stoll K, Hall WA. Attitudes and preferences of young women with low and high fear of childbirth. Qual Health Res. 2013;23:1495-1505.

76. Christiaens W, Van De Velde, S. V., Bracke P. Pregnant women's fear of childbirth in midwife- and obstetrician-led care in Belgium and the Netherlands: test of the medicalization hypothesis. Women Health. 2011;51:220-239.

77. Gottman JM, Notarius Cl. Marital research in the 20th century and a research agenda for the 21st century. Fam Process. 2002;41:159-197.

78. Pacey S. Couples and the first baby: responding to new parents' sexual and relationship problems. Sex Relatsh Ther. 2004;19:223-246.

79. Hildingsson I. Swedish couples' attitudes towards birth, childbirth fear and birth preferences and relation to mode of birth - a longitudinal cohort study. Sex Reprod Healthc. 2014;5:75-80.

\section{Tables}

\section{Table 1}




\begin{tabular}{|c|c|c|c|c|c|}
\hline Name of instrument & $\begin{array}{l}\text { \# of } \\
\text { items }\end{array}$ & $\begin{array}{l}\text { Subscales include at } \\
\text { least three items? }\end{array}$ & $\begin{array}{l}\text { Complete } \\
\text { content } \\
\text { coverage }\end{array}$ & $\begin{array}{l}\text { Excludes non- } \\
\text { fear content }\end{array}$ & $\begin{array}{l}\text { For use with } \\
\text { pregnant people? }\end{array}$ \\
\hline N/A - No name (4) & 53 & NO & MED & NO & YES \\
\hline $\begin{array}{l}\text { Slade-Pais Expectations of Childbirth Scale } \\
\text { (SPECS) (29) }\end{array}$ & 50 & YES & $\mathrm{HIGH}$ & NO & YES \\
\hline $\begin{array}{l}\text { Wijma Delivery Expectancy/Experience } \\
\text { Questionnaire - Version A (W-DEQ-A) (18) }\end{array}$ & 33 & YES & LOW & NO & YES \\
\hline N/A - No name (19) & 29 & YES & LOW & NO & NO \\
\hline Tokophobia Severity Scale (TSS) (20) & 13 & $\mathrm{~N} / \mathrm{A}$ & MED & NO & YES \\
\hline Fear of Vaginal Delivery Scale (17) & 10 & N/A & MED & NO & NO \\
\hline Birth Experiences Questionnaire (BEQ) (26) & 10 & $\mathrm{~N} / \mathrm{A}$ & LOW & NO & NO \\
\hline Oxford Worries about Labour Scale (OWLS) (28) & 9 & Not all & $\mathrm{HIGH}$ & YES & YES \\
\hline Birth Anticipation Scale (BAS) (21) & 6 & N/A & LOW & YES & YES \\
\hline No name (27) & 6 & $\mathrm{~N} / \mathrm{A}$ & - & - & - \\
\hline Fear of Birth Scale (FOBS) (22) & 2 & $\mathrm{~N} / \mathrm{A}$ & LOW & YES & YES \\
\hline Visual Analogue Scale (VAS) (25) & 1 & $\mathrm{~N} / \mathrm{A}$ & LOW & YES & YES \\
\hline No name (23) & 1 & $\mathrm{~N} / \mathrm{A}$ & LOW & YES & YES \\
\hline No name (24) & 1 & $\mathrm{~N} / \mathrm{A}$ & LOW & YES & YES \\
\hline
\end{tabular}

\section{Table 2}

Participant Demographic and Reproductive Information. 


\begin{tabular}{|c|c|c|c|c|}
\hline \multirow[t]{2}{*}{ Demographic variables } & \multicolumn{2}{|c|}{ Study $1(N=643)$} & \multicolumn{2}{|c|}{ Study $2(\mathrm{~N}=881)$} \\
\hline & Percentage & $\mathbf{n}$ & Percentage & $\mathbf{n}$ \\
\hline Married or cohabitating & $93.0 \%$ & 598 & $93.3 \%$ & 819 \\
\hline Some postsecondary education & $85.9 \%$ & 520 & $96.8 \%$ & 829 \\
\hline \multicolumn{5}{|l|}{ Country of residence } \\
\hline Canada & $63.6 \%$ & 409 & $100 \%$ & 881 \\
\hline United States & $30.8 \%$ & 198 & $\mathrm{~N} / \mathrm{A}$ & N/A \\
\hline United Kingdom & $2.6 \%$ & 17 & N/A & N/A \\
\hline European heritage & $92.7 \%$ & 596 & $72.5 \%$ & 636 \\
\hline English spoken at home & $94.1 \%$ & 605 & $94.3 \%$ & 826 \\
\hline \multicolumn{5}{|l|}{ Current pregnancy } \\
\hline Singleton pregnancy & $97.4 \%$ & 626 & $97.3 \%$ & 854 \\
\hline Weeks pregnant: M (SD) & $22.2(10.4)$ & 643 & $34.9(2.5)$ & 870 \\
\hline Pregnancy complications & $22.9 \%$ & 147 & $33.4 \%$ & 293 \\
\hline \multicolumn{5}{|l|}{ Reproductive history } \\
\hline Prior births & $76.3 \%$ & $n=296$ & $65.9 \%$ & $\mathrm{n}=324$ \\
\hline Vaginal & $80.7 \%$ & 239 & $81.8 \%$ & 251 \\
\hline Cesarean & $25.7 \%$ & 76 & $31.0 \%$ & 85 \\
\hline Prior pregnancy loss $<20$ weeks & $50.3 \%$ & 195 & $39.2 \%$ & 193 \\
\hline Prior pregnancy loss $>20$ weeks & $3.9 \%$ & 15 & $1.6 \%$ & 8 \\
\hline Questionnaire data & M & SD & M & SD \\
\hline W-DEQ-A & 55.9 & 23.5 & 58.2 & 23.0 \\
\hline EPDS & 7.8 & 5.1 & 7.7 & 5.0 \\
\hline MQ & 11.1 & 6.4 & N/A & N/A \\
\hline PDS-5 & $\mathrm{N} / \mathrm{A}$ & N/A & 9.9 & 11.9 \\
\hline
\end{tabular}

Table 3 - Study 1

Model Fit Indexes, Information Criteria, and Model Comparisons for 1-13 Factor EFA Solutions

\begin{tabular}{|c|c|c|c|c|c|c|c|}
\hline \# of Factors & $x^{2}$ & $d f$ & RMSEA & TLI & $\mathrm{BIC}$ & $\Delta \chi^{2}$ & $\Delta d f$ \\
\hline 1 & $14390.42^{\star \star \star}$ & 1127 & .137 & .405 & 7103.07 & - & - \\
\hline 2 & $10789.4^{\star \star \star}$ & 1079 & .116 & .544 & 3812.43 & 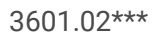 & 48 \\
\hline 3 & $7965.64^{\star \star \star ~}$ & 1032 & .104 & .659 & 1292.58 & $2823.76^{\star \star \star}$ & 47 \\
\hline 4 & $5796.91^{\star \star \star}$ & 986 & .089 & .752 & -578.71 & $2168.73^{\star \star \star}$ & 46 \\
\hline 5 & $4959.07 * \star \star$ & 941 & .083 & .783 & -1125.57 & $837.84^{\star \star \star}$ & 45 \\
\hline 6 & $4332.69 * \star \star$ & 897 & .079 & .805 & -1467.44 & $626.38 * \star \star$ & 44 \\
\hline 7 & $3712.56^{\star \star \star}$ & 854 & .074 & .830 & -1809.53 & $620.13^{\star \star \star}$ & 43 \\
\hline 8 & 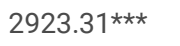 & 812 & .065 & .867 & -2327.2 & $789.25^{\star \star \star}$ & 42 \\
\hline 9 & $2448.91 * * *$ & 771 & .060 & .889 & -2536.49 & $474.40 * \star *$ & 41 \\
\hline 10 & $2092.93^{\star \star \star}$ & 731 & .055 & .905 & -2633.83 & $355.98 * \star \star$ & 40 \\
\hline 11 & $1766.84^{\star \star \star}$ & 692 & .051 & .921 & -2707.73 & $326.09 * \star \star$ & 39 \\
\hline 12 & $1549.77^{\star \star \star \star ~}$ & 654 & .048 & .930 & -2679.09 & 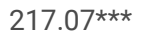 & 38 \\
\hline $13^{\mathrm{a}}$ & 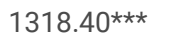 & 617 & .044 & .942 & -2671.21 & 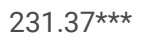 & 37 \\
\hline
\end{tabular}




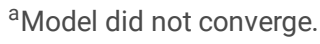

$\star \star \star *<.001$

Table 4

Oblimin-Rotated Factor Loadings from Pattern Matrix of 9-Factor CFQ Solution

Page 16/21 


\begin{tabular}{|c|c|c|c|c|c|c|c|c|c|}
\hline Item Content & F1 & $\mathrm{F} 2$ & F3 & $\mathrm{F} 4$ & F5 & F6 & F7 & F8 & F9 \\
\hline \multicolumn{10}{|c|}{ Factor 1: Fear of Loss of Sexual Pleasure/Attractiveness (SEX) } \\
\hline Vaginal stretching from vaginal birth & 0.659 & 0.102 & -0.020 & 0.027 & 0.055 & -0.005 & 0.000 & 0.032 & 0.184 \\
\hline Body look less attractive following birth & 0.541 & 0.099 & -0.042 & 0.094 & -0.004 & 0.089 & -0.058 & 0.122 & 0.039 \\
\hline Vagina look less attractive following birth & 0.823 & 0.037 & -0.018 & 0.094 & -0.048 & 0.038 & -0.002 & 0.047 & -0.003 \\
\hline Enjoying sex less $\mathrm{b} / \mathrm{c}$ of stretching & 0.894 & -0.026 & 0.024 & -0.032 & 0.002 & -0.068 & 0.091 & -0.055 & -0.002 \\
\hline Partner enjoy sex less b/c of stretching & 0.902 & 0.020 & -0.030 & 0.065 & 0.017 & 0.049 & -0.018 & -0.009 & -0.054 \\
\hline Enjoying sex less b/c of pain & 0.710 & -0.024 & 0.044 & -0.058 & 0.129 & -0.033 & 0.025 & -0.013 & 0.062 \\
\hline \multicolumn{10}{|c|}{ Factor 2: Fear of Pain from a Vaginal Birth (PAIN) } \\
\hline Experiencing pain during contractions & 0.015 & 0.957 & 0.029 & -0.002 & 0.020 & 0.010 & 0.007 & 0.012 & -0.062 \\
\hline Experiencing pain during vaginal birth & 0.019 & 0.795 & -0.018 & 0.041 & 0.016 & -0.033 & 0.020 & 0.020 & 0.110 \\
\hline Experiencing pain during labour & 0.018 & 0.974 & 0.032 & -0.022 & 0.021 & 0.002 & -0.005 & 0.022 & -0.030 \\
\hline Experiencing pain pushing baby out & 0.002 & 0.835 & -0.047 & 0.046 & 0.002 & -0.003 & 0.032 & 0.016 & 0.085 \\
\hline Having a vaginal birth & -0.063 & 0.359 & 0.020 & 0.079 & 0.017 & -0.196 & 0.041 & 0.138 & 0.277 \\
\hline \multicolumn{10}{|l|}{ Factor 3: Fear of Medical Interventions (INT) } \\
\hline Experiencing pain during cesarean birth & -0.003 & 0.109 & 0.580 & -0.049 & -0.009 & 0.148 & 0.094 & 0.104 & 0.013 \\
\hline Harmed because of incompetent care & 0.014 & -0.116 & 0.602 & 0.087 & 0.166 & 0.048 & 0.085 & -0.022 & -0.031 \\
\hline Being left with scars from cesarean birth & 0.201 & -0.081 & 0.451 & -0.105 & -0.062 & 0.214 & -0.062 & 0.163 & 0.064 \\
\hline Being administered injections & -0.055 & 0.051 & 0.559 & 0.146 & 0.001 & 0.039 & -0.024 & -0.169 & 0.038 \\
\hline Having catheter inserted & 0.056 & 0.050 & 0.504 & 0.150 & 0.008 & 0.069 & -0.013 & -0.073 & 0.101 \\
\hline Having general anesthetic & 0.015 & -0.004 & 0.440 & 0.020 & 0.060 & 0.187 & -0.109 & -0.092 & 0.134 \\
\hline Being administered epidural & -0.014 & 0.152 & 0.446 & 0.063 & -0.011 & 0.126 & -0.068 & -0.319 & 0.099 \\
\hline \multicolumn{10}{|l|}{ Factor 4: Fear of Embarrassment (SHY) } \\
\hline Being watched by strangers & -0.016 & -0.089 & 0.351 & 0.520 & -0.031 & -0.015 & 0.029 & 0.006 & 0.034 \\
\hline Losing emotional control & 0.167 & 0.101 & 0.016 & 0.446 & 0.071 & -0.003 & -0.140 & 0.036 & 0.066 \\
\hline Others seeing me urinate & 0.049 & -0.015 & 0.025 & 0.766 & -0.008 & -0.008 & 0.063 & 0.011 & 0.052 \\
\hline Others seeing me bowel & 0.098 & 0.071 & -0.103 & 0.681 & 0.066 & 0.049 & 0.007 & 0.085 & 0.002 \\
\hline Others seeing me naked & 0.033 & 0.067 & 0.011 & 0.755 & 0.009 & -0.079 & 0.038 & 0.045 & -0.025 \\
\hline \multicolumn{10}{|l|}{ Factor 5: Fear of Harm to Baby (HARM) } \\
\hline Baby being harmed during labor/birth & 0.001 & 0.058 & -0.039 & 0.013 & 0.924 & -0.015 & 0.044 & 0.018 & -0.001 \\
\hline Baby being damaged during labor/birth & 0.058 & 0.041 & -0.062 & 0.011 & 0.886 & -0.002 & 0.046 & 0.010 & -0.008 \\
\hline Baby being hurt by medical intervention & -0.014 & -0.089 & 0.249 & -0.011 & 0.654 & 0.095 & 0.108 & 0.012 & 0.055 \\
\hline \multicolumn{10}{|l|}{ Factor 6: Fear of Cesarean Birth (CS) } \\
\hline Not being able to have birth i want & 0.002 & -0.052 & -0.025 & 0.028 & 0.077 & 0.792 & 0.015 & 0.116 & 0.043 \\
\hline Not being able to have vaginal birth & 0.004 & -0.008 & -0.038 & -0.036 & 0.001 & 0.932 & 0.014 & -0.034 & -0.021 \\
\hline Having a cesarean birth & 0.021 & 0.104 & 0.331 & -0.046 & -0.084 & 0.581 & 0.056 & -0.034 & 0.000 \\
\hline \multicolumn{10}{|l|}{ Factor 7: Fear of Baby or Mom Dying (DEATH) } \\
\hline Baby dying during labor/birth & 0.000 & 0.030 & 0.000 & 0.006 & 0.071 & 0.025 & 0.899 & -0.012 & -0.013 \\
\hline Baby suffocating during labour/birth & 0.013 & 0.001 & -0.037 & 0.005 & -0.001 & 0.006 & 0.955 & 0.015 & 0.041 \\
\hline Dying during labor/birth & 0.129 & 0.007 & 0.277 & 0.072 & 0.089 & -0.048 & 0.377 & 0.146 & -0.135 \\
\hline \multicolumn{10}{|c|}{ Factor 8: Fear of Insufficient Pain Medication (MEDS) } \\
\hline Not getting needed pain meds & 0.016 & 0.097 & 0.044 & 0.078 & 0.048 & 0.033 & 0.033 & 0.794 & 0.002 \\
\hline Not having epidural during labour & 0.000 & 0.059 & -0.027 & 0.040 & 0.026 & 0.027 & 0.043 & 0.790 & 0.050 \\
\hline
\end{tabular}




\begin{tabular}{|c|c|c|c|c|c|c|c|c|c|}
\hline Not being able to have c-section & 0.033 & -0.093 & 0.030 & 0.083 & 0.068 & -0.149 & 0.030 & 0.297 & 0.201 \\
\hline \multicolumn{10}{|l|}{ Factor 9: Fear of Body Damage (DAMAGE) } \\
\hline Vaginal tearing during birth & 0.107 & 0.135 & -0.150 & 0.044 & 0.053 & 0.010 & 0.074 & 0.028 & 0.685 \\
\hline Rectal tearing during birth & 0.061 & 0.025 & 0.011 & 0.140 & 0.151 & 0.005 & 0.112 & 0.065 & 0.553 \\
\hline Having an episiotomy & 0.012 & 0.083 & 0.263 & -0.002 & -0.024 & 0.075 & 0.024 & -0.012 & 0.496 \\
\hline Requiring vacuum or forceps & -0.008 & -0.019 & 0.220 & 0.020 & 0.297 & 0.155 & -0.045 & 0.035 & 0.394 \\
\hline Needing stitches & 0.207 & 0.122 & 0.057 & 0.068 & -0.078 & 0.037 & 0.130 & 0.028 & 0.483 \\
\hline \multicolumn{10}{|l|}{ Discarded Items } \\
\hline Not being strong & 0.109 & 0.182 & -0.112 & 0.340 & 0.129 & 0.241 & -0.044 & 0.043 & 0.024 \\
\hline Receiving unwanted pain meds & -0.007 & -0.115 & 0.322 & 0.164 & 0.121 & 0.294 & 0.024 & -0.271 & 0.119 \\
\hline Feeling pressure to receive pain meds & -0.053 & -0.008 & 0.217 & 0.159 & -0.004 & 0.332 & 0.096 & -0.314 & 0.106 \\
\hline Feeling pressure to have natural birth & 0.005 & 0.149 & -0.044 & 0.185 & -0.043 & 0.033 & 0.121 & 0.289 & -0.036 \\
\hline Baby contract illness during labour/birth & 0.104 & -0.065 & 0.088 & -0.015 & 0.195 & -0.055 & 0.338 & 0.118 & 0.039 \\
\hline Bleeding too much during labour/birth & 0.156 & 0.066 & 0.258 & 0.105 & 0.155 & -0.087 & 0.177 & 0.121 & -0.047 \\
\hline Being left with scars from vaginal birth & 0.323 & 0.047 & 0.192 & -0.096 & 0.090 & -0.124 & -0.056 & 0.209 & 0.334 \\
\hline Having scars/wounds not heal & 0.218 & -0.029 & 0.238 & 0.104 & 0.116 & 0.060 & 0.049 & 0.168 & 0.153 \\
\hline Vomiting during labour/birth & 0.050 & 0.139 & -0.005 & 0.239 & -0.012 & -0.028 & 0.170 & -0.022 & 0.184 \\
\hline
\end{tabular}

Table 5

Correlations among the CFQ Subscales and Total Score for Study 1 (S1) and Study 2 (S2)

\begin{tabular}{|c|c|c|c|c|c|c|c|c|c|c|c|c|c|c|c|c|c|c|}
\hline Fear of... & SEX & & PAIN & & INT & & SHY & & HARN & & $\mathrm{CS}$ & & DEAT & & MEDS & & DAMA & \\
\hline & $\mathrm{S} 1$ & $\mathrm{~S} 2$ & S1 & $\mathrm{S} 2$ & S1 & $\mathrm{S} 2$ & S1 & $\mathrm{S} 2$ & $\mathrm{~S} 1$ & $\mathrm{~S} 2$ & $\mathrm{~S} 1$ & $\mathrm{~S} 2$ & S1 & $\mathrm{S} 2$ & $\mathrm{~S} 1$ & S2 & S1 & $\mathrm{S} 2$ \\
\hline 1. SEX & - & & & & & & & & & & & & & & & & & \\
\hline 2. PAIN & $.53^{\star \star}$ & $.48^{\star \star}$ & - & & & & & & & & & & & & & & & \\
\hline 3. INT & $.22^{\star *}$ & $.34^{\star *}$ & $.08^{* *}$ & $.34^{* *}$ & - & & & & & & & & & & & & & \\
\hline 4. SHY & $.59^{\star *}$ & $.51^{\star *}$ & $.49^{\star *}$ & $.50^{\star *}$ & $.34^{* *}$ & $.40^{\star *}$ & - & & & & & & & & & & & \\
\hline 5. HARM & $.49^{\star \star}$ & $.38^{\star *}$ & $.33^{* \star}$ & $.38^{\star \star}$ & $.30^{\star \star}$ & $.50^{\star \star}$ & $.40^{\star \star}$ & $.35^{\star \star}$ & - & & & & & & & & & \\
\hline 6. CS & $.13^{*}$ & $.11^{\star *}$ & -.01 & $.11^{*}$ & $.60^{\star *}$ & $.59^{\star \star}$ & $.16^{\star \star}$ & $.18^{* \star}$ & $.27^{* \star}$ & $.31^{\star *}$ & - & & & & & & & \\
\hline $\begin{array}{l}7 . \\
\text { DEATH }\end{array}$ & $.45^{\star *}$ & $.38^{\star *}$ & $.35^{\star *}$ & $.38^{\star *}$ & $.23^{\star *}$ & $.45^{* *}$ & $.42^{\star *}$ & $.36^{\star *}$ & $.78^{* *}$ & $.79^{* *}$ & $.20^{\star *}$ & $.22^{\star *}$ & - & & & & & \\
\hline 8. MEDS & $.50^{\star *}$ & $.37^{\star *}$ & $.59^{\star *}$ & $.62^{\star *}$ & -.03 & $.25^{* *}$ & $.40^{\star *}$ & $.41^{* *}$ & $.43^{* *}$ & $.36^{* *}$ & -.04 & -.03 & $.43^{* *}$ & $.35^{\star *}$ & - & & & \\
\hline $\begin{array}{l}9 . \\
\text { DAMAGE }\end{array}$ & $.62^{\star *}$ & $.55^{\star \star}$ & $.56^{* *}$ & $.64^{\star \star}$ & $.45^{\star *}$ & $.54^{\star \star}$ & $.54^{\star \star}$ & $.51^{\star \star}$ & $.57^{\star \star}$ & $.59^{\star *}$ & $.31^{\star \star}$ & $.34^{\star *}$ & $.47^{* *}$ & $.50^{\star *}$ & $.42^{* \star}$ & $.47^{\star *}$ & - & \\
\hline Total & $.78^{\star \star}$ & $.69^{\star *}$ & $.66^{* *}$ & $.74^{\star \star}$ & $.58^{\star *}$ & $.74^{\star *}$ & $.73^{\star *}$ & $.68^{\star *}$ & $.73^{\star *}$ & $.73^{* *}$ & $.43^{\star *}$ & $.46^{* *}$ & $.68^{* *}$ & $.69^{* *}$ & $.56^{\star *}$ & $.58^{\star *}$ & $.84^{* *}$ & $.84^{* *}$ \\
\hline
\end{tabular}

Table 6

CFQ Total and Subscale Means and Standard Deviations. 


\begin{tabular}{lll} 
Subscale & $\begin{array}{l}\text { Study } 1 \\
(\mathrm{~N}=643)\end{array}$ & $\begin{array}{l}\text { Study } 2 \\
(\mathrm{~N}=874)\end{array}$ \\
\hline Fear of... & $M(S D)$ & $M(S D)$ \\
\hline SEX: Loss of sexual pleasure / attractiveness & $1.20(1.10)$ & $0.82(0.78)$ \\
\hline PAIN: Fear of pain from a vaginal birth & $1.65(1.10)$ & $1.36(1.02)$ \\
\hline INT: Medical interventions & $1.72(.97)$ & $1.05(0.74)$ \\
\hline SHY: Fear of embarrassment & $1.15(0.95)$ & $0.64(0.66)$ \\
\hline HARM: Fear of harm to baby & $2.25(1.32)$ & $1.57(1.04)$ \\
\hline CS: Fear of cesarean birth & $2.29(1.23)$ & $1.69(1.09)$ \\
\hline DEATH: Fear of mom or baby dying & $1.68(1.30)$ & $1.34(1.14)$ \\
\hline MEDS: Fear of insufficient pain medication & $0.80(0.94)$ & $0.60(0.76)$ \\
\hline DAMAGE: Fear of body damage from a vaginal birth & $1.89(1.05)$ & $1.52(0.89)$ \\
\hline CFQ Total Mean Scores & $1.59(0.73)$ & $1.14(0.61)$
\end{tabular}

Note. All scores are mean item scores with a possible range of 0 (not at all) to 4 (extremely).

\section{Table 7}

CFQ Subscale Means and Standard Deviations: By Delivery Preference and Country.

\begin{tabular}{|c|c|c|c|c|c|c|}
\hline \multirow[t]{2}{*}{ Subscale } & \multicolumn{2}{|c|}{ Birth Preferences } & \multicolumn{2}{|l|}{ Parity } & \multicolumn{2}{|c|}{ Nationality } \\
\hline & $\begin{array}{l}\text { Vaginal } \\
(n=539)\end{array}$ & $\begin{array}{l}\text { Cesarean } \\
(n=33)\end{array}$ & $\begin{array}{l}\text { Nulliparous } \\
(n=347)\end{array}$ & $\begin{array}{l}\text { Multiparous } \\
(n=296)\end{array}$ & $\begin{array}{l}\text { Canada } \\
(n=409)\end{array}$ & $\begin{array}{l}\text { USA } \\
(n=198)\end{array}$ \\
\hline Fear of... & $M(S D)$ & $M(S D)$ & $M(S D)$ & $M(S D)$ & $M(S D)$ & $M(S D)$ \\
\hline Loss of sexual pleasure / attractiveness & $1.1(1.1)$ & $1.4(1.3)$ & $1.4(1.10)$ & $0.9(1.0)^{\star \star \star}$ & $1.2(1.1)$ & $1.2(1.1)$ \\
\hline Fear of pain from a vaginal birth & $1.5(1.0)$ & $2.3(1.4)^{\star \star}$ & $2.0(1.1)$ & $1.3(1.0)^{\star \star \star}$ & $1.6(1.1)$ & $1.7(1.1)$ \\
\hline Medical interventions & $1.8(1.0)$ & $1.4(0.9)^{*}$ & $1.7(0.9)$ & $1.7(1.0)$ & $1.7(1.0)$ & $1.9(1.0)^{*}$ \\
\hline Fear of embarrassment & $1.1(0.9)$ & $1.2(1.1)$ & $1.4(1.0)$ & $0.9(0.9)^{\star \star \star}$ & $1.1(0.9)$ & $1.2(.9)$ \\
\hline Fear of harm to baby & $2.2(1.3)$ & $2.9(1.5)^{\star \star}$ & $2.4(1.3)$ & $2.1(1.3)^{\star \star}$ & $2.3(1.3)$ & $2.1(1.3)$ \\
\hline Fear of cesarean birth & $2.5(1.1)$ & $1.3(1.0)^{\star \star \star}$ & $2.2(1.2)$ & $2.4(1.26)$ & $2.2(1.2)$ & 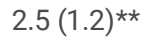 \\
\hline Fear of mom or baby dying & $1.6(1.3)$ & $2.3(1.2)^{\star \star}$ & $1.7(1.3)$ & $1.7(1.3)$ & $1.6(1.3)$ & $1.8(1.3)$ \\
\hline Fear of insufficient pain medication & $0.7(0.8)$ & $2.0(1.4)^{\star \star \star}$ & $0.9(1.0)$ & $0.6(0.9)^{\star \star \star}$ & $0.8(0.9)$ & $.8(1.0)$ \\
\hline Fear of body damage from a vaginal birth & $1.9(1.0)$ & $1.9(1.5)$ & $2.1(1.0)$ & $1.6(1.0)^{\star \star \star}$ & $1.9(1.1)$ & $1.8(1.0)$ \\
\hline CFQ Total Mean Scores & $1.6(0.7)$ & $1.8(1.0)$ & $1.7(0.7)$ & $1.4(0.7)^{\star \star \star}$ & $1.6(0.7)$ & $1.6(.7)$ \\
\hline
\end{tabular}

Note. All scores are mean item scores with a possible range of 0 (not at all) to 4 (extremely).

${ }^{*} p<0.05 ;{ }^{* *} p<0.01 ; * \star * \quad p<0.001$, based on t-tests for independent samples comparing women who: (a) prefer a vaginal birth to those who prefer a Cesarean birth, (b) are nulliparous to women who are multiparous, and (c) are resident of Canada to those who are resident of the United States of America.

\section{Table 8}

Model Fit Indexes for CFA Model and Invariance between Nationality (Canada vs. USA) and Parity (Primiparous vs. Multiparous) Groups 


\begin{tabular}{lccccccccc} 
Model & $\chi^{2}$ & $d f$ & CFI & TLI & RMSEA 90\% Cl & SRMR & $\Delta \chi^{2}$ & $\Delta d f$ & $\Delta C F I$ \\
\hline CFA & $1981.26 * \star \star$ & 683 & .93 & .92 & $.056, .062$ & .05 & - & - & -
\end{tabular}

Invariance (Nationality)

\begin{tabular}{llllllllll}
\hline Configural & $2799.21 * \star \star$ & 1366 & .92 & .91 & $.059, .065$ & .06 & - & - & - \\
\hline Weak & $2874.15^{\star \star \star}$ & 1418 & .92 & .91 & $.058, .065$ & .06 & $76.69 *$ & 52 & .001 \\
\hline Strong & $2927.91 * \star \star$ & 1449 & .92 & .91 & $.055, .061$ & .06 & $52.65^{\star \star}$ & 31 & .001
\end{tabular}

Invariance (Parity)

\begin{tabular}{llllllllll}
\hline Configural & $2790.74 * * *$ & 1366 & .91 & .90 & $.059, .065$ & .06 & - & - & - \\
\hline Weak & $2864.79 * \star \star$ & 1418 & .91 & .90 & $.058, .065$ & .06 & $76.67 *$ & 52 & .001 \\
\hline Strong & $2943.60 * \star \star$ & 1449 & .91 & .90 & $.058, .065$ & .06 & $80.08 * \star \star$ & 31 & .003
\end{tabular}

Note. $\chi^{2}$ is Yuan-Bentler corrected version, based on robust MLR estimation; $\Delta \chi^{2}$ is therefore computed using scaled Satorra-Bentler (2001) method

\section{Figures}

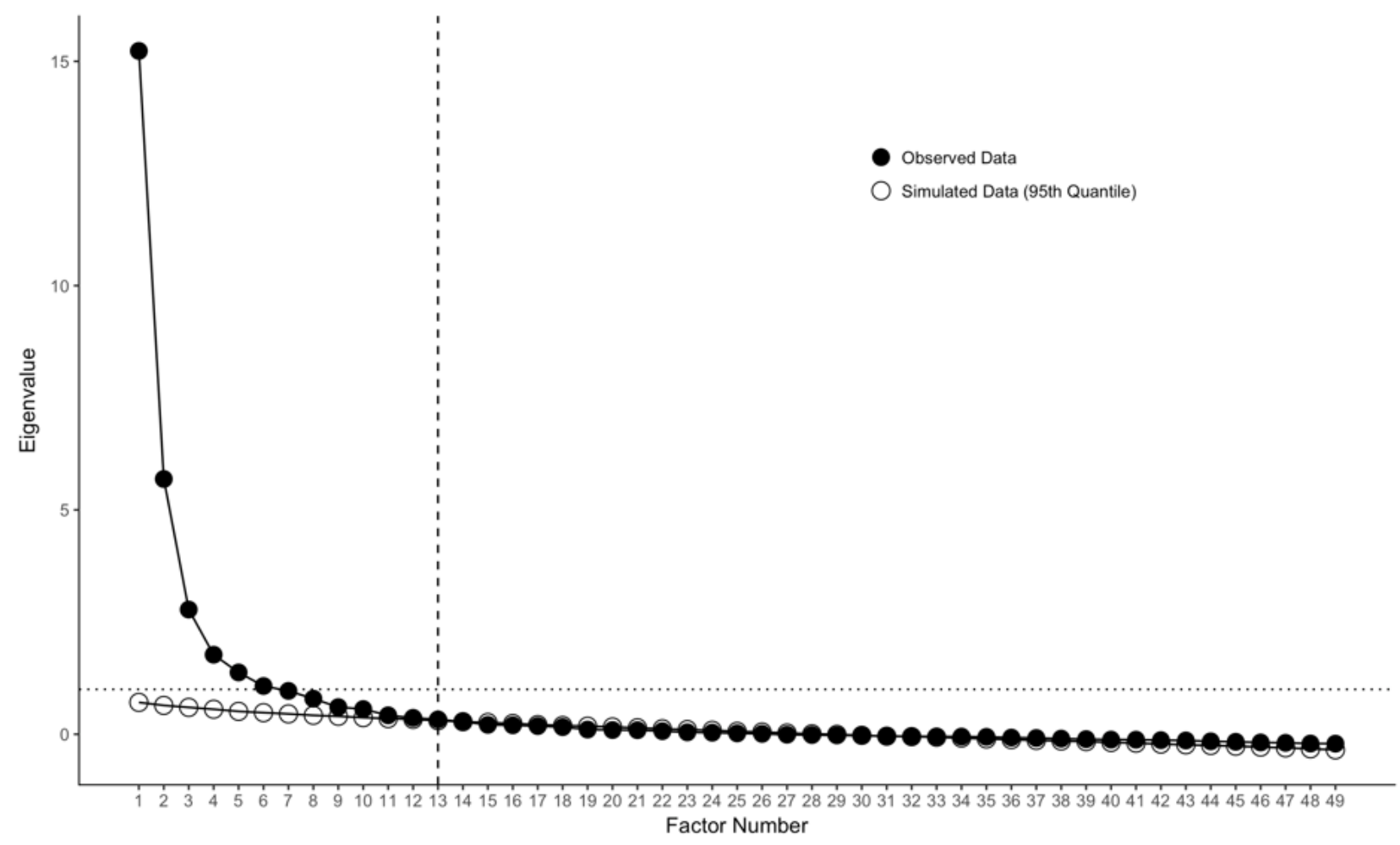

Figure 1

Parallel analysis of $49 \mathrm{CFQ}$ items. Vertical dashed line indicates maximum recommended number of factors (last observed eigenvalue that is larger than 95th quantile of simulated eigenvalues). Horizontal dotted line indicates eigenvalue of 1. 
CCFI Profiles

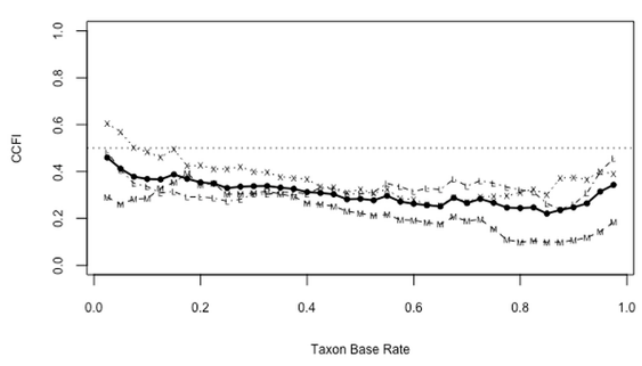

CCFI Profiles

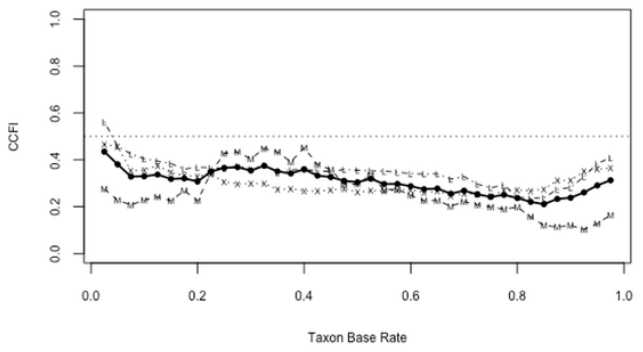

CCFI Profiles

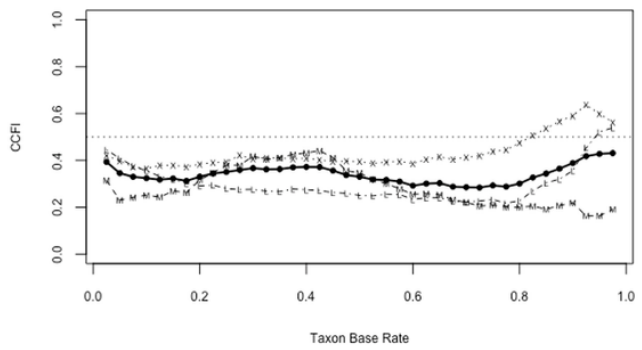

Figure 2

CCFI profiles from taxometric analyses of three unique sets of CFQ indicators. $M=$ MAMBAC, $X=M A X E I G, L=L-M O D E$, and solid dots $=$ the average CCFI. 